\title{
Differential Responses of Cakile maritima at Two Development Stages to Salinity: Changes on Phenolic Metabolites and Related Enzymes and Antioxidant Activity
}

Rim Ben Mansour ${ }^{1^{\star}}$, Sara Dakhlaouia ${ }^{1}$, Wissal Msahli ${ }^{2}$, Riadh Ksouri' ${ }^{1}$ and Wided Megdiche-Ksouri

${ }^{1}$ Laboratoire des Plantes Aromatiques et Médicinales, Centre de Biotechnologie à la Technopôle de Borj-Cédria (CBBC), BP 901, 2050 Hammam-lif, Tunisia

${ }^{2}$ Laboratoire des Légumineuses, Centre de Biotechnologie à la Technopôle de Borj-Cédria (CBBC), BP 901, 2050 Hammam-lif, Tunisia

\begin{abstract}
Though halophytes are naturally adapted to salinity, their salt-tolerance limits are greatly influenced by endogenous (that is, physiological development stages) and exogenous factors (that is, salinity). In this work, the evaluation of oxidative stress, bioactive molecules contents, antioxidant activities and two enzymes involved in the synthesis of secondary metabolites were assessed in the edible halophytic species Cakile maritima as function of salinity $(0,100,400 \mathrm{mM} \mathrm{NaCl})$ and two physiological stages. Total phenols, flavonoids and tannin contents increased by 58,80 and $18 \%$ in vegetative period and by 27,28 and $31 \%$ in flowering one at $400 \mathrm{mM} \mathrm{NaCl}$, respectively as compared to $C$. maritima shoots control. These data indicated that phenolic compounds played an important role in protecting this species from salinity. The stimulatory effect of the salt on the total phenols content leads to the investigation of the role of two regulatory shikimate/phenylpropanoid pathway enzymes in phenolic synthesis. Results indicated that increased treatment progressively stimulated positively the activities of phenylalanine ammonia lyase and shikimate kinase in the vegetative and flowering period. Increasing salinity is correlated to the accumulation of carotenoids, anthocyanin, proline and ascorbate contents. The antioxidant activity enhanced at the vegetative stage in salt condition as compared to the flowering one. These results strongly indicate that salinity induces the accumulation of secondary metabolites in $C$. maritima shoots by altering the phenolic synthesis enzymes, as well as for the up-regulation of antioxidant molecules defense.
\end{abstract}

Keywords: Cakile maritima; Antioxidant activity; Phenylalanine ammonia-lyase; Shikimate kinase; Salt treatment; Development stage

\section{Introduction}

Abiotic stresses are considered to be serious threats to plants and vegetation since they decrease crop yield and quality. Among these, salinity is the major abiotic factor that causes important damages to plants. This phenomenon is more severe in the semi-arid and arid areas [1]. In fact, increased salinity induces specific changes at cell, tissue and organ levels and it disrupts different biochemical and physiological processes [2]. Salt stress leads to osmotic imbalance by limiting absorption of water from soil and to ionic stress resulting from high concentrations of potentially toxic salt ions within the cells [3]. It also generates oxidative stress in plant tissues which is manifested by reactive oxygen species (ROS) such as singlet oxygen, superoxide anion, hydrogen peroxide and hydroxyl radical [1]. Consequently, plants that grow well in high salinity have specific structural and physiological adaptations to cope with the altered processes, while maintaining their reproductive capacity [2]. Among them, halophytes have the ability to withstand the stressful environmental conditions using different mechanisms including their capacity to quench toxic ROS, since they are equipped with powerful antioxidant system that includes enzymatic and non-enzymatic components.

The biosynthesis and the accumulation of these secondary metabolites, such as polyphenol, are generally stimulated in response to biotic/abiotic constraints [4]. Consequently, one may hypothesize that optimal polyphenol yield would be obtained using stress-tolerant species [5]. These components are synthesized through aromatic amino acids starts with the shikimate pathway. Shikimate kinase (EC 2.7.1.71) is the enzyme responsible for converting shikimate to 3-phosphoshikimate, a committed step in the biosynthesis of chorismate [6]. The latter is the branching point metabolite and the major precursor of aromatic amino acids, folates, ubiquinones, and many other aromatic compounds. The aromatic amino acids formed in this pathway are then used for protein synthesis or converted, in the phenylpropanoid metabolism, into secondary metabolites such as lignin or phenolics and phytoalexins [7].
At the gateway from primary metabolism, L-Phenylalanine Ammonia Lyase (PAL, EC 4.3.1.5) plays a pivotal role in phenolic synthesis and thousands of reports emphasize the correlation between increases in the corresponding PAL gene/protein expression/activity and increases in phenolic compounds in response to different stimuli and stress factors [7]. PAL seems to be very sensitive to the physiological state of the plant like during pathological events and plays an important role in plant defense. It is also involved in the biosynthesis of the signaling molecules and salicylic acid which is required for plant systemic resistance [8,9]. In addition, there is an increasing interest for other antioxidant molecules like ascorbic acid (Vit C, ASC). In fact, ASC is crucial for plant defence against oxidative stress. It is a watersoluble antioxidant molecule, used as substrate for ascorbate peroxydase which catalyzes hydrogen peroxide detoxification. ASC acts directly to eliminate superoxide radicals, ${ }^{1} \mathrm{O}_{2}$, and as a secondary antioxidant during reductive recycling of the oxidized form of tocopherol [10] and protecting enzymes with prosthetic transition metal ions [11].

It was shown that the amount of bioactive compounds and antioxidant activities in plants are controlled by biological factors (genotype, organ and ontogeny), edaphic and environmental (temperature, salinity, water stress and light intensity) conditions. According to Lisiewska et al. [12], the evolution of phenolic content in

*Corresponding author: Rim Ben Mansour, Laboratoire des Plantes Aromatiques et Médicinales, Centre de Biotechnologie à la Technopôle de Borj-Cédria (CBBC), BP 901, 2050 Hammam-lif, Tunisia, Tel: +21679412848; E-mail: rim.bmansour@gmail.com

Received April 17, 2018; Accepted April 20, 2018; Published April 26, 2018

Citation: Mansour RB, Dakhlaouia S, Msahli W, Ksouri R, Megdiche-Ksouri W (2018) Differential Responses of Cakile maritima at Two Development Stages to Salinity: Changes on Phenolic Metabolites and Related Enzymes and Antioxidan Activity. Med Chem (Los Angeles) 8: 100-108. doi: 10.4172/2161-0444.1000500

Copyright: ( 2018 Mansour RB, et al. This is an open-access article distributed under the terms of the Creative Commons Attribution License, which permits unrestricted use, distribution, and reproduction in any medium, provided the original author and source are credited. 
Citation: Mansour RB, Dakhlaouia S, Msahli W, Ksouri R, Megdiche-Ksouri W (2018) Differential Responses of Cakile maritima at Two Development Stages to Salinity: Changes on Phenolic Metabolites and Related Enzymes and Antioxidant Activity. Med Chem (Los Angeles) 8: 100-108. doi: 10.4172/2161-0444.1000500

higher plants may reflect their physiological status and developmental stages. In this context, Ksouri et al. [4] indicated that leaf and stem extracts of Salsola kali showed a significant decrease of their phenolic contents and consequently their antiradical activities at the reproductive stage, as compared to the vegetative one, while root extract showed the opposite tendency. Other studies reports that phenolic content varied as a function of plant growth in tomato and Anethum graveolens cultivars $[12,13]$. Studies have also found antioxidant properties to be influenced by various environmental factors for several plants. In fact, polyphenol synthesis and accumulation is generally stimulated in response to biotic/abiotic stresses such as salinity [14]. In this context, Oueslati et al. [15] showed an increase of total polyphenol content (2.41-8.17 mg gallic acid equivalent $\mathrm{g}^{-1} \mathrm{DW}$ ) in the leaves of a medicinal plant Mentha pulegium $\mathrm{L}$. under salt constraints.

In this context, we investigated the effect of salt treatment and development stage on the bioactive metabolite contents, antioxidant capacities and the enzymatic activities of the PAL and the shikimate kinase, in the halophytic species C. maritima (Brassicaceae), traditionally used for its purgative, diuretic and antiscorbutic properties and for culinary applications [3]

\section{Materials and Methods}

\section{Plant material, culture conditions and preparation of extract}

Cakile maritima seeds were harvested in August 2016 at Raoued, a locality close to the Mediterranean seashore, $20 \mathrm{~km}$ north of Tunis. Germination of seeds was conducted for one week in the dark and at room temperature. After that, seedlings were sown in pots (four seedlings per pot) filled with inert sand and irrigated daily with Hewitt nutrient solution ( $\mathrm{pH} 7.3$, electrical conductivity $2.7 \mathrm{mS} \mathrm{cm}^{-1}$ ) [16] for 4 weeks. Seedlings were partitioned into three lots of plants grown of four individuals each and $\mathrm{NaCl}$ was added to the solution. The final salt concentration $(0,100$ or $400 \mathrm{mM})$ was progressively adjusted with increasing $\mathrm{NaCl}$ concentrations (50 $\mathrm{mM}$ step per day). The culture was conducted in greenhouse under controlled environment (15$25^{\circ} \mathrm{C}$ temperature and $70-90 \%$ relative humidity, $16 / 8 \mathrm{~h}$ day/night photoperiod). Aerial parts of the plant were collected at two different developmental stages, vegetative and flowering. Shoots were dried at $35^{\circ} \mathrm{C}$ for one week. Plant extracts were obtained by magnetic stirring of $2 \mathrm{~g}$ of dry matter powder with $20 \mathrm{ml}$ of methanol $80 \%$ for $30 \mathrm{~min}$. Then, extracts were kept at $4^{\circ} \mathrm{C}$ for $24 \mathrm{~h}$, filtered through a Whatman No. 4 filter paper and stored at $4^{\circ} \mathrm{C}$ until analysis. Besides, fresh shoots samples from each plant were used for performing the biochemical analysis.

\section{Evaluation of stress indicators}

Lipid peroxidation: Lipid peroxidation was estimated by determining the malonyldialdehyde (MDA) contents [17]. Amount of $200 \mathrm{mg}$ of fresh samples were homogenised in $1 \mathrm{ml}$ of $0.1 \%(\mathrm{w} / \mathrm{v})$ trichloroacetic acid (TCA). The homogenate was centrifuged at 15000 $g$ for $10 \mathrm{~min}$ at $4^{\circ} \mathrm{C}$. The supernatant was mixed $(\mathrm{v} / \mathrm{v})$ with $0.5 \%(\mathrm{w} / \mathrm{v})$ thiobarbituric acid (TBA) prepared in TCA $20 \%$, and incubated at $90^{\circ} \mathrm{C}$ for $30 \mathrm{~min}$. After stopping the reaction in an ice bath, samples were centrifuged at $10000 \mathrm{~g}$ for $10 \mathrm{~min}$. The supernatant absorbance at 532 $\mathrm{nm}$ was then measured. After subtracting the non-specific absorbance at $600 \mathrm{~nm}, \mathrm{MDA}$ concentration (three replicates per treatment) was determined using the extinction coefficient $\left(155 \mathrm{mM}^{-1} \mathrm{~cm}^{-1}\right)$.

Electrolytes Leakage (EL): Leaf disks (100 mg) of uniform size (5 $\mathrm{mm}$ diameter) were placed in test tubes containing $10 \mathrm{ml}$ of double distilled water. The tubes were incubated in a water bath at $32^{\circ} \mathrm{C}$ for
$2 \mathrm{~h}$ and the initial electrical conductivity of the medium (EC1) was measured. The samples were incubated again in a water bath at $95^{\circ} \mathrm{C}$ for $20 \mathrm{~min}$ to release all electrolytes then cooled to $25^{\circ} \mathrm{C}$ before measuring the final electrical conductivity (EC2). The EL percentage was calculated using the formula:

\section{$\mathrm{EL}=(\mathrm{EC} 1 / \mathrm{EC} 2) \times 100$}

Pigments analyses: Carotenoid and anthocyanin contents $(\mu \mathrm{g} / \mathrm{g}$ Fresh Weight) in the aerial parts were measured based on the method described by Gould et al. [18].

The extraction of carotenoid was realized with $200 \mathrm{mg}$ of plant material frozen in liquid $\mathrm{N}_{2}$, ground to a fine powder (on ice) and then mixed with two milliliters of acetone: $\mathrm{H}_{2} \mathrm{O}(4: 1, \mathrm{v} / \mathrm{v})$. The mixture was agitated and left in the dark at $4^{\circ} \mathrm{C}$ for 72 hours. The extracts were centrifuged and the absorbance was measured with UV/visible spectrophotometer at three different wave lengths. Measurements of $A_{470}, A_{647}$ and $A_{663}$ were taken to calculate the concentrations of total carotenoids according to the following equation:

$$
\text { Carotenoid (CAR, } \mu \mathrm{g} / \mathrm{g})=5 A_{(470)}+2.846 A_{(663)}-14.876 A_{(647)}
$$

Anthocyanin content was assayed with $200 \mathrm{mg}$ of plant material frozen in liquid $\mathrm{N}_{2}$, ground to a fine powder in a mortar placed on ice, then two milliliters of a $\mathrm{HCl}: \mathrm{H}_{2} \mathrm{O}: \mathrm{MeOH}(1: 3: 16, \mathrm{v} / \mathrm{v} / \mathrm{v})$ solution were added. The mixture was agitated and kept in the dark at $4^{\circ} \mathrm{C}$ for 72 hours. The extracts were centrifuged and the absorbance was measured with UV/visible spectrophotometer. Anthocyanin levels were estimated using the formula: $A_{530}-0.24 A_{653}$. The subtraction of $0.24 A_{653}$ compensated the small overlap in absorbance at $530 \mathrm{~nm}$ by the chlorophylls [19]. Triplicate measurements were taken for all samples.

Ascorbic acid quantification: The assay is based on the reduction of $\mathrm{Fe}^{3+}$ to $\mathrm{Fe}^{2+}$ by AsA and the spectrophotometric detection of $\mathrm{Fe}^{2+}$ complexed with 2,2'-dipyridyl method [20]. DHA is reduced to AsA by preincubation of the sample with dithiothreitol (DTT). Subsequently, the excess of DTT is removed with $N$-ethylmaleimide (NEM) and total AsA is determined by the 2,2'-dipyridyl method. The concentration of DHA is then calculated from the difference of total AsA and AsA (without pre-treatment with DTT). Aerial parts of treated and untreated plants were shock frozen in liquid $\mathrm{N}_{2}$. Aliquots of frozen plant material $(0.4 \mathrm{~g})$ were ground to a fine powder in a mortar (placed in ice), prechilled with liquid $\mathrm{N}_{2}$ before adding $0.8 \mathrm{ml} 6 \%(\mathrm{w} / \mathrm{v})$ TCA. After grinding in the frozen TCA, the mixture was continually homogenized until completely thawed and then allowed to stand further on ice for 15 $\mathrm{min}$. The homogenate was adjusted to a volume of $2 \mathrm{ml}$ with $6 \%(\mathrm{w} / \mathrm{v})$ TCA, then centrifuged for $5 \mathrm{~min}$ at $15600 \mathrm{~g}\left(4^{\circ} \mathrm{C}\right)$ and the supernatant was immediately assayed for total vitamin $\mathrm{C}$ and AsA. The following solutions are used: standard solution of AsA dissolved in 6\% (w/v) TCA, $10 \mathrm{mM}$ DTT dissolved in $0.2 \mathrm{M}$ phosphate buffer ( $\mathrm{pH} 7.4$ ), $0.5 \%$ (w/v) NEM, $10 \%(\mathrm{w} / \mathrm{v})$ TCA, $42 \%$ (w/v) $\mathrm{H}_{3} \mathrm{PO}_{4}, 4 \%$ (w/v) 2,2'-dipyridyl dissolved in $70 \%(\mathrm{v} / \mathrm{v})$ ethanol, and $3 \%(\mathrm{w} / \mathrm{v}) \mathrm{FeCl}_{3}$. The absorbance was read at $525 \mathrm{~nm}$. A standard curve covering the range of 0-25 nmol AsA was used. Triplicate measurements were taken for all samples.

Proline quantification: Proline was extracted using dried plant material. The experiment was conducted on ice and $10 \mathrm{mg}$ of plant samples were dissolved in $750 \mu \mathrm{l}$ of $3 \%(\mathrm{w} / \mathrm{v})$ aqueous sulfosalicilic acid and centrifuged at $14000 \mathrm{~g}$ for $10 \mathrm{~min}$. The supernatant was kept and the pellet was redissolved in $750 \mu \mathrm{l}$ sulfosalicilic acid for a second extraction. The amount of proline was measured by the colometric method described by Bates et al. [21] using ninhydrin, acetic acid and orthophosphoric acid complex. $1 \mathrm{~mL}$ of the plant extract was mixed with $1 \mathrm{~mL}$ of the ninhydrin reagent and $1 \mathrm{ml}$ of glacial acetic acid and 
Citation: Mansour RB, Dakhlaouia S, Msahli W, Ksouri R, Megdiche-Ksouri W (2018) Differential Responses of Cakile maritima at Two Development Stages to Salinity: Changes on Phenolic Metabolites and Related Enzymes and Antioxidant Activity. Med Chem (Los Angeles) 8: 100-108. doi: 10.4172/2161-0444.1000500

immediately incubated at $100^{\circ} \mathrm{C}$ for one hour. Tubes were cooled (on ice) and $2 \mathrm{~mL}$ of pure toluene were added to the mixture which was strongly shaken for 40 to 45 seconds. The upper layer of the coloured solution is used for the absorbance lecture at $520 \mathrm{~nm}$. Proline final concentrations were determined referring to a standard curve $(0-10 \mu \mathrm{g}$ proline $/ \mathrm{mL}$ ). Each sample was measured three times.

\section{Colorimetric quantification of phenolics}

Determination of total polyphenol content: Phenolic content was assayed using the Folin-Ciocalteu reagent, following Singleton's method slightly modified [22]. An aliquot $(0.125 \mathrm{~mL})$ of appropriately diluted sample extract was added to $0.5 \mathrm{ml}$ of distilled water and 0.125 $\mathrm{mL}$ of the Folin-Ciocalteu reagent. After $3 \mathrm{~min}, 1.25 \mathrm{~mL}$ of $\mathrm{Na}_{2} \mathrm{CO}_{3}$ $(7 \%, w / v)$ solution were added and the final volume was brought to 3 $\mathrm{ml}$ with distilled water. The absorbance was measured at $760 \mathrm{~nm}$, after incubation for $90 \mathrm{~min}$ at room temperature in dark. Total polyphenol content of plant extracts was expressed as mg gallic acid equivalents per gram of dry weight (mg GAE/g DW) through the calibration curve with gallic acid. The calibration curve range was $0-400 \mu \mathrm{g} / \mathrm{mL}$. Triplicate measurements were taken for each sample.

Estimation of total flavonoid content: The amount of flavonoid content was measured using the method described by Dewanto et al. [22]. An aliquot of suitable diluted sample or standard solution of (+)-catechin was added to a $\mathrm{NaNO}_{2}$ solution and kept for 6 min before adding $0.15 \mathrm{ml}$ of a freshly prepared $\mathrm{AlCl}_{3}$ solution $(10 \% \mathrm{w} / \mathrm{v})$. After $5 \mathrm{~min}, 0.5 \mathrm{ml}$ of $1 \mathrm{M} \mathrm{NaOH}$ solution was added. The final volume was adjusted to $2.5 \mathrm{ml}$ with distilled water and thoroughly mixed. Absorbance of the mixture was determined at $510 \mathrm{~nm}$. Total flavonoids were expressed as $\mathrm{mg}(+)$-catechin equivalent per gram dry weight $(\mathrm{mg}$ $\mathrm{CE} / \mathrm{g} \mathrm{DW})$, through the calibration curve of (+)-catechin.

Total condensed tannins content: Contents of condensed tannins were carried out according to Sun et al. [23]. $50 \mu \mathrm{L}$ of properly diluted sample were mixed with $3 \mathrm{ml}$ of vanillin-methanol solution $(4 \% \mathrm{w} / \mathrm{v})$ and $1.5 \mathrm{ml}$ of concentrated hydrochloric acid. The mixture was left for $15 \mathrm{~min}$ and the absorption was measured at $500 \mathrm{~nm}$. The concentration of condensed tannins was expressed as $\mathrm{mg}(+)$-equivalent catechin/g DW. The calibration curve range of catechin was established between 0 and $400 \mu \mathrm{g} / \mathrm{mL}$. All samples were analysed in triplicate.

\section{Shikimate/Phenypropanoid pathway enzymes}

Assay of the shikimate kinase (SK): Fresh tissue was homogenized at $4^{\circ} \mathrm{C}$ in a grinding medium containing $0.1 \mathrm{M} \mathrm{K}$-phosphate buffer (pH 7.4), $0.5 \mathrm{mM}$ DTT, $2 \mathrm{mM}$ l-cysteine, $2 \mathrm{mM}$ EDTA, $8 \mathrm{mM}$ $\beta$-mercaptoethanol and $0.5 \mathrm{~g}$ PVPP. The homogenates were filtred individually through four layer of gauze and centrifuged at $19000 \mathrm{~g}$ for 20 min at $0-4^{\circ} \mathrm{C}[24]$.

The shikimate kinase (EC 2.7.1.71) was assayed at $25^{\circ} \mathrm{C}$ by coupling the release of ADP to the oxidation of $\mathrm{NADH}$ using pyruvate kinase (EC 2.7.1.40) and lactate deshydrogenase (EC1.1.1.27) as coupling enzymes according to Krell et al. [25]. Shikimate dependent oxidation of NADH was monitored at $340 \mathrm{~nm}$. The assay mixture contained $50 \mathrm{mM}$ triethanolamine hydrochloride/KOH buffer at $\mathrm{pH} 7.0,50$ $\mathrm{mM} \mathrm{KCl}, 5 \mathrm{mM} \mathrm{MgCl}, 1.6 \mathrm{mM}$ shikimic acid, $5 \mathrm{mM}$ ATP, $1 \mathrm{mM}$ phosphoenolpyruvate, $0.1 \mathrm{mM} \mathrm{NADH}, 3$ units/ml pyruvate kinase, 2.5 units/ml lactate dehydrogenase and $1 \mathrm{ml}$ of the enzyme crude extract. The enzymatic activity was calculated using the extinction coefficient $\varepsilon=6,22 \mathrm{mM}^{-1} \mathrm{~cm}^{-1}$.

Assay of the phenylalanine ammonia lyase (PAL): The extract enzyme preparation for phenylalanine ammonia lyase (PAL; EC
4.3.1.5) was obtained by homogenizing $5 \mathrm{~g}$ of fresh material in $10 \mathrm{ml}$ of the extraction medium containing $0.1 \mathrm{M}$ sodium borate buffer $(\mathrm{pH}$ 8.8), $20 \mathrm{mM} \beta$-mercaptoethanol and 5\% PVPP $(\mathrm{m} / \mathrm{v})$. The homogenate was centrifuged at $16000 \mathrm{~g}$ at $4^{\circ} \mathrm{C}$ for $20 \mathrm{~min}$. The enzyme activity was measured by adding $250 \mu \mathrm{l}$ of the supernatent to $1 \mathrm{ml} \mathrm{L}$-phenylalanine $(0.1 \mathrm{M})$ and $1.75 \mathrm{ml}$ sodium borate buffer $(\mathrm{pH} 8.8)$. After 1 hour incubation at $37^{\circ} \mathrm{C}$, the reaction was stopped by adding $100 \mu \mathrm{l} 6 \mathrm{~N} \mathrm{HCl}$ and the absorbance was read at $290 \mathrm{~nm}$ [26].

\section{Determination of antioxidant activities}

Total antioxidant capacity: Total antioxidant activity of methanolic extracts was evaluated according to the method described by Prieto et al. [27], based on the formation of a green phosphate $/ \mathrm{Mo}^{5+}$ complex. An aliquot $(0.1 \mathrm{~mL})$ of appropriately diluted samples was added to 1 $\mathrm{mL}$ of reagent solution $(0.6 \mathrm{M}$ sulfuric acid, $28 \mathrm{mM}$ sodium phosphate and $4 \mathrm{mM}$ ammonium molybdate). Methanol (80\%) was used instead of sample for the blank. The tubes were incubated in a boiling water bath for $90 \mathrm{~min}$. Then, samples were cooled to room temperature and the absorbance was measured at $695 \mathrm{~nm}$ using a UV-Visible spectrophotometer. Antioxidant capacity was expressed as $\mathrm{mg}$ gallic acid equivalent per gram dry weight (mg GAE/g DW). All samples were analyzed in triplicate.

DPPH scavenging activity: The scavenging activity of C. maritima extracts was measured in term of hydrogen donating or radical scavenging ability using the DPPH method [28]. One milliliter of various concentrations $(100-1000 \mu \mathrm{g} / \mathrm{mL})$ of the methanolic extracts was mixed with $0.25 \mathrm{~mL}$ of a $0.2 \mathrm{mM} \mathrm{DPPH}$ methanolic solution. The mixture was vigourously shaken and placed in the dark at room temperature for $30 \mathrm{~min}$. The absorbance of the resulting solution was then read at $517 \mathrm{~nm}$. The antiradical activity was expressed as $\mathrm{IC}_{50}(\mu \mathrm{g}$. $\mathrm{mL}^{-1}$ ). The ability to scavenge the DPPH radical was calculated using the following equation:

$$
\text { DPPH scavenging effect }(\%)=\left[\left(A_{0}-A_{1}\right) / A_{0}\right] \times 100
$$

Where $\mathrm{A}_{0}$ is the absorbance of the control at $30 \mathrm{~min}$, and $\mathrm{A}_{1}$ is the absorbance of the sample at $30 \mathrm{~min}$. All samples were analyzed in triplicate.

Iron reducing power: The ability of the extracts to reduce $\mathrm{Fe}^{3+}$ was assayed by the method of Oyaizu [29]. Briefly, $1 \mathrm{ml}$ of C. aritime extracts at different concentrations (500-10000) was mixed with $2.5 \mathrm{ml}$ of phosphate buffer $(0.2 \mathrm{M}, \mathrm{pH} 6.6)$ and $2.5 \mathrm{ml}$ of potassium ferricyanide $(1 \% \mathrm{w} / \mathrm{v})$. After incubation at $50^{\circ} \mathrm{C}$ for $20 \mathrm{~min}, 2.5 \mathrm{ml}$ of trichloroacetic acid $(10 \% \mathrm{w} / \mathrm{v})$ was added and the mixture was centrifuged at $650 \mathrm{~g}$ for $10 \mathrm{~min}$. Finally, $2.5 \mathrm{ml}$ of the upper layer was mixed with $2.5 \mathrm{ml}$ of distilled water and $0.5 \mathrm{ml}$ of aqueous ferric chloride $(0.1 \% \mathrm{w} / \mathrm{v})$. The absorbance was measured at $700 \mathrm{~nm}$. Increased absorbance of the reaction mixture indicated increasing reducing power. $\mathrm{EC}_{50}$ value $(\mu \mathrm{g}$. $\mathrm{ml}^{-1}$ ) is the effective concentration at which the absorbance was 0.5 obtained from linear regression.

$\beta$-Carotene bleaching test (BCBT): A slightly modified Koleva et al. [30] method was employed to estimate Cakile aerial parts capacity to inhibit the bleaching of the $\beta$-carotene. Two milligram of $\beta$-carotene was dissolved in $20 \mathrm{ml}$ chloroform and to $4 \mathrm{ml}$ of this solution, linoleic acid $(40 \mathrm{mg})$ and Tween $40(400 \mathrm{mg})$ were added. Under vacuum at $40^{\circ} \mathrm{C}$, the chloroform was evaporated and $100 \mathrm{ml}$ of oxygenated water was added, then the emulsion was vigorously shaken. An aliquot (150 $\mu \mathrm{l})$ of the $\beta$-carotene/linoleic acid emulsion was distributed in each of the wells of 96-well plate and methanolic solutions of the test samples $(10 \mu \mathrm{l})$ were added. Three replicates were prepared for each of the 
Citation: Mansour RB, Dakhlaouia S, Msahli W, Ksouri R, Megdiche-Ksouri W (2018) Differential Responses of Cakile maritima at Two Development Stages to Salinity: Changes on Phenolic Metabolites and Related Enzymes and Antioxidant Activity. Med Chem (Los Angeles) 8: $100-108$. doi: 10.4172/2161-0444.1000500

samples concentration. The plate was incubated at $50^{\circ} \mathrm{C}$ for $120 \mathrm{~min}$, and the absorbance was measured using a model EAR 400 microtitre reader (Labsystems Multiskan MS) at $470 \mathrm{~nm}$. Reading of all samples were performed immediately ( $\mathrm{t}=0 \mathrm{~min}$ ) and after $120 \mathrm{mn}$ incubation. The antioxidant activity (AA) of the extracts was evaluated in term of inhibition of the bleaching of the $\beta$-carotene using the formula below and the results were expressed as inhibition percentage values.

$\beta$-carotene bleaching inhibition $(\%)=\left[\left(\mathrm{A}_{\mathrm{c}(120)}-\mathrm{A}_{\mathrm{s}(120)}\right) /\left(\mathrm{A}_{\mathrm{c}(0)}-\mathrm{A}_{\mathrm{c}(120)}\right)\right]$ $\times 100$

where $\mathrm{A}_{\mathrm{c}(0)}$ and $\mathrm{A}_{\mathrm{C}(120)}$ are the absorbance values of the control at 0 and $120 \mathrm{~min}$, respectively, and $\mathrm{A}_{\mathrm{s}(120)}$ is the sample absorbance at 120 $\mathrm{min}$. The results were expressed as $\mathrm{IC}_{50}$ values $\left(\mu \mathrm{g} \cdot \mathrm{ml}^{-1}\right)$.

Statistical analysis: A two-way analysis of variance (ANOVA), with the physiological stage (D) and salt treatment (S) as factors, was performed for the whole data set using the STATI-CF statistical program. Means were compared using the Newman-Keuls test at the $\mathrm{p}<0.05$ level when significant differences were found. Values were the means of three replicates.

\section{Results}

\section{Lipid peroxidation and electrolytes leakage}

The effect of salinity on C. maritima at both development stages, measured using the MDA formation and the electrolytes leakage (EL), seem to be more dependent on the salt treatment $(S)$. These observations are confirmed by statistical analysis where the effect of salinity on the plants leads to significant differences. The two indices of oxidative stress studied have a similar response to salinity levels (Figure 1). The lipid peroxidation in the aerial parts of the plant, during the vegetative stage, increased significantly by $56 \%$ and $41 \%$ at 100 and $400 \mathrm{mM} \mathrm{NaCl}$ as compared to the control. In flowering stage, MDA accumulation was significantly lower than that in vegetative one. Similarly, electrolytes leakage was significantly correlated with salinity (Figure 1). It increased in all treatments, and was higher in vegetative period (2.2 and 2.9 times

\begin{tabular}{|c|c|c|c|}
\hline Dependent variables & (D) & (S) & $(S \times D)$ \\
\hline MDA & 3.052 & $155.425^{\star \star *}$ & $9.810^{* *}$ \\
\hline EL & 6.071 & $64.691^{* * *}$ & 1.229 \\
\hline Carotenoids & 7.839 & $104.261^{* * *}$ & 0.000 \\
\hline Antocyanins & $10.406^{\star}$ & $8.101^{* *}$ & 0.092 \\
\hline Total Vit. C & $13.977^{*}$ & $81.271^{* \star *}$ & $9.350^{* *}$ \\
\hline AsA & $3245.673^{\star * *}$ & $663.429^{* * *}$ & $486.544^{* * *}$ \\
\hline DHA & $3186.497^{\star * *}$ & $800.409^{\star \star *}$ & $459.351^{* * *}$ \\
\hline Proline & $742.755^{* * *}$ & $545.868^{* * *}$ & $186.903^{* * *}$ \\
\hline Polyphenols & 0.001 & $22.875^{\star \star *}$ & $2.737^{*}$ \\
\hline Flavonoids & $134.331^{* * *}$ & $19.049^{* \star *}$ & 0.375 \\
\hline Tannins & $26.810^{\star * *}$ & 6.346 & 0.549 \\
\hline PAL & $444.609^{* * *}$ & $425.014^{* * *}$ & $52.938^{* * *}$ \\
\hline SK & 0.009 & $11.981^{* *}$ & $33.852^{* * *}$ \\
\hline DPPH & $1309.688^{* * *}$ & $126.140^{\star * *}$ & $64.204^{* * *}$ \\
\hline TAA & $1003.913^{* * *}$ & $37.142^{* \star *}$ & 1.862 \\
\hline Reducing power & $533.929^{* * *}$ & $399.617^{* * *}$ & $63.832^{* * *}$ \\
\hline BCBT test & $20.152^{\star *}$ & $25.822^{\star \star *}$ & 0.693 \\
\hline
\end{tabular}

Results of ANOVA: $F$ values for the proportion of total variance attributed to the physiological development stage (D), salt treatment $(S)$ and their interaction $(S \times$ D). Numbers represent $F$ values: ${ }^{*} P<0.01$, ${ }^{* *} P<0.001$, ${ }^{\star * *} P<0.0001$.

Table 1: Comparison of the development stage and the salt treatment on antioxidant compounds and activities (antioxidant and enzymatic). higher respectively at $100 \mathrm{mM}$ and $400 \mathrm{mM}$ ) than in the flowering one (1.5 and 2 times higher at $100 \mathrm{mM}$ and $400 \mathrm{mM}$, respectively) as compared to the untreated plants.

\section{Change of amounts of antioxidant pigments, proline and ascorbic acids as function of salinity and physiological development stage}

Carotenoid and anthocyanin contents of C. maritima showed a wide range ( 11.5 to $31.7 \mu \mathrm{g} \mathrm{g}^{-1} \mathrm{FW}$ and 1.1 to $2.5 \mu \mathrm{g} \mathrm{g}^{-1} \mathrm{FW}$, respectively) (Figure 2a and 2b). Results displayed that salt treatment (S) seems to be the determinant factor in the amount of these molecules as it was depicted by the analysis of variance and as it is shown by results presented in Table 1. In fact, there is a significant increase in the amount of carotenoids as function of the salt dose rising for plants collected in the both periods of growth. Many previous works showed that the amounts of these molecules increased with salinity [31].

Ascorbic acid content (reduced ascorbic acid (AsA) and dehydroascorbate (DHA)) in the aerial parts of Cakile maritima was found to be significantly variable (Figure 3 ). Our results showed a particular wealth of this species in vitamin $\mathrm{C}$ when compared to other plants. Its content is about $400 \mathrm{mg} / 100 \mathrm{~g} \mathrm{FW}$ and this was recorded within the control plants. The variation of the total ascorbic acid content was proportional to the salt doses and it is the highest at 400 $\mathrm{mM} \mathrm{NaCl}$ (Figure 3a) where it is 445.3 and $444.8 \mathrm{mg} / 100 \mathrm{~g} \mathrm{FW}$ during the vegetative and the reproductive stages, respectively. This result corroborate with those reported by Hafsi et al. [32] and Telesinski et al. [33], where they showed that a salt treatment increases the production of vitamin $\mathrm{C}$ and is salt-dose dependent.

The oxidized fraction (DHA) increased as function of salinity while the reduced fraction (AsA) decreased, especially at $400 \mathrm{mM}$ $\mathrm{NaCl}$ (Figure $3 \mathrm{~b}$ and $3 \mathrm{c}$ ). These results corroborate with those found by Ben Amor et al. [34] in two different localities of C. maritima. These authors found that prolonged exposure to high salinity (200 and 400 $\mathrm{mmol} / \mathrm{L} \mathrm{NaCl}$ ) caused a decrease in reduced ascorbate and an increase in oxidized ascorbate, which was matched by a substantial decrease in the ASC/DHA ratio. This can indicate that the reduced form of the ascorbic acid interfere in the protection of the plant in the case of salt stress by being oxidized.

A highly significant effect of salinity (S), development stage (D) and their interaction $\left(S^{\star} D\right)$ on shoot proline was found (Table 1). The quantification of this amino acid indicated that its amount increased with salt doses for both stages particularly the vegetative one (Figure 4), suggesting the positive role of proline in the salt tolerance.

\section{Change in phenolic metabolism as function of salinity and physiological development stage}

As shown in Table 2, salt-challenged plants of C. maritima exhibited a significant increase in polyphenol accumulation (up to $58.3 \%$ at 400 $\mathrm{mM}$ in the vegetative stage), while there is no significant variability in the total phenolic content between the two development stages. These results were corroborated by ANOVA statistical analysis (Table 1) which showed that no significant effect was described by (D). However, (S) contributed by the highest proportion of total variance, followed by $(\mathrm{S} \times \mathrm{D})$. As an important fraction of total phenolic, flavonoid content of C. maritima shoots showed significant differences (Table 2). Results displayed that (S) and (D) significantly influenced flavonoid content (Table 1). With similar tendency to phenolics, flavonoid content was remarkably higher in salt-challenged plants with the highest amounts found during the flowering period of the plant. Concerning the 
Citation: Mansour RB, Dakhlaouia S, Msahli W, Ksouri R, Megdiche-Ksouri W (2018) Differential Responses of Cakile maritima at Two Development Stages to Salinity: Changes on Phenolic Metabolites and Related Enzymes and Antioxidant Activity. Med Chem (Los Angeles) 8: 100-108. doi: 10.4172/2161-0444.1000500

\begin{tabular}{|c|c|c|c|c|c|c|}
\hline \multirow{2}{*}{$\begin{array}{c}\text { Development stage } \\
\mathrm{NaCl}(\mathrm{mM})\end{array}$} & \multicolumn{3}{|c|}{ Vegetative period } & \multicolumn{3}{|c|}{ Flowering period } \\
\hline & 0 & 100 & 400 & 0 & 100 & 400 \\
\hline $\begin{array}{c}\text { Total polyphenol content (mg GAE/g } \\
\text { DW) }\end{array}$ & $4.8 \pm 0.04 \mathrm{~d}$ & $5.7 \pm 0.01 \mathrm{~cd}$ & $7.6 \pm 0.02 \mathrm{a}$ & $5.3 \pm 0.03 \mathrm{~cd}$ & $6.1 \pm 0.00 \mathrm{bc}$ & $6.7 \pm 0.01 \mathrm{ab}$ \\
\hline $\begin{array}{c}\text { Total flavonoid content (mg CE/g } \\
\text { DW) }\end{array}$ & $0.5 \pm 0.0 \mathrm{~d}$ & $0.6 \pm 0.00 \mathrm{~d}$ & $0.9 \pm 0.00 \mathrm{c}$ & $1.1 \pm 0.01 b$ & $1.2 \pm 0.01 b$ & $1.4 \pm 0.00 \mathrm{a}$ \\
\hline Tanin content (mg CE/g DW) & $1.1 \pm 0.00 \mathrm{c}$ & $1.2 \pm 0.00 \mathrm{c}$ & $1.3 \pm 0.00 \mathrm{bc}$ & $1.3 \pm 0.00 \mathrm{bc}$ & $1.5 \pm 0.01 \mathrm{ab}$ & $1.7 \pm 0.00 \mathrm{a}$ \\
\hline
\end{tabular}

mg GAE/g DW: milligram gallic acid equivalent per gram dry weight; mg CE/g DW: milligram catechin equivalent per gram dry weight

Table 2: Variation of total polyphenol, flavonoid and condensed tannin contents in aerial parts of Cakile maritima as function of salinity ( 0 , 100 and 400 mM NaCl) and physiological development stage (vegetative and flowering). Means (three replicates) followed by at least one same letter are not significantly different at $\mathrm{P}<0.01$.

\begin{tabular}{|c|c|c|c|c|c|c|}
\hline \multirow{2}{*}{$\begin{array}{c}\text { Development stage } \\
\mathrm{NaCl}(\mathrm{mM})\end{array}$} & \multicolumn{3}{|c|}{ Vegetative period } & \multicolumn{3}{|c|}{ Flowering period } \\
\hline & 0 & 100 & 400 & 0 & 100 & 400 \\
\hline TAA (mg GAE/g DW) & $29.6 \pm 0.03 b$ & $32.1 \pm 0.01 \mathrm{a}$ & $34 \pm 0.01 \mathrm{a}$ & $11.6 \pm 0.02 \mathrm{e}$ & $15.1 \pm 0.06 \mathrm{~d}$ & $18.5 \pm 0.04 \mathrm{c}$ \\
\hline DPPH test $\mathrm{IC}_{50}(\mu \mathrm{g} / \mathrm{ml})$ & $310 \mathrm{~b}$ & $260 a b$ & $240 \mathrm{a}$ & $330 \mathrm{e}$ & $650 \mathrm{~d}$ & $480 \mathrm{c}$ \\
\hline Iron reducing power $\mathrm{EC}_{50}(\mathrm{mg} / \mathrm{ml})$ & $4.44 \mathrm{~b}$ & $4.38 \mathrm{~b}$ & $2.38 \mathrm{a}$ & $6.19 \mathrm{~d}$ & $4.61 \mathrm{c}$ & $4.26 \mathrm{~b}$ \\
\hline BCBT test IC ${ }_{50}(\mathrm{mg} / \mathrm{ml})$ & $9.15 \mathrm{c}$ & $5.68 \mathrm{ab}$ & $3.73 \mathrm{a}$ & $12.6 \mathrm{~d}$ & $7.44 \mathrm{bc}$ & $7.35 \mathrm{bc}$ \\
\hline
\end{tabular}

$\mathrm{mg} \mathrm{GAE/g} \mathrm{DW:} \mathrm{milligram} \mathrm{gallic} \mathrm{acid} \mathrm{equivalent} \mathrm{per} \mathrm{gram} \mathrm{dry} \mathrm{weight}$

Table 3: Variation of the antioxidant activities of methanolic extract in Cakile maritima leaves as function of salinity $(0,100$ and $400 \mathrm{mM} \mathrm{NaCl})$ and physiological development stage (vegetative and flowering). Means (three replicates) followed by at least one same letter are not significantly different at $P<0.01$.

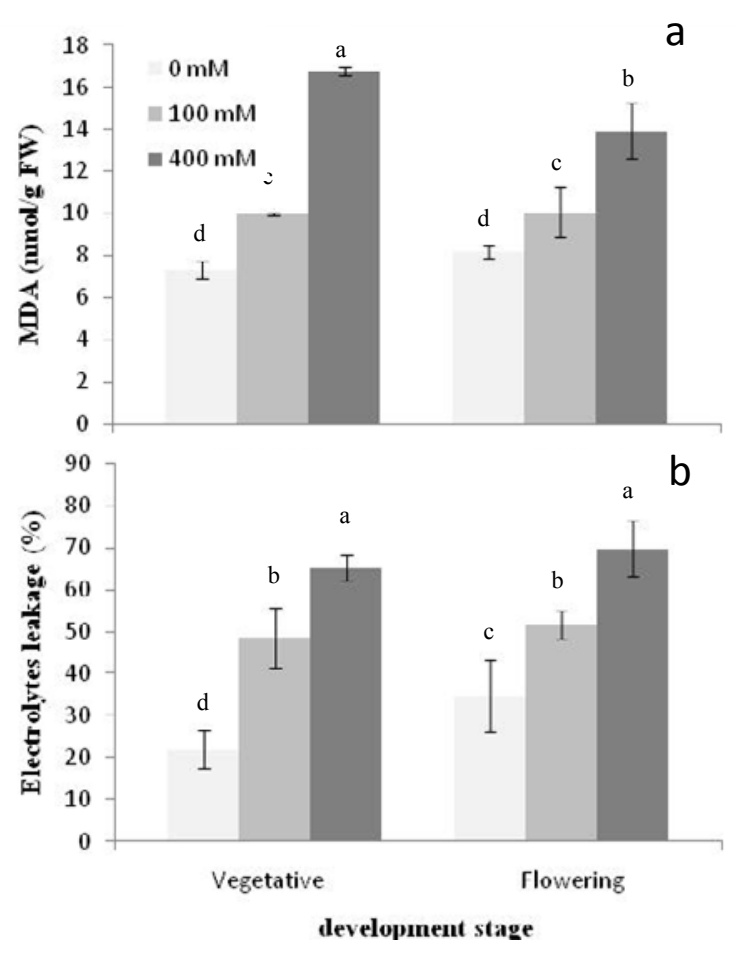

Figure 1: Variation of MDA (a) content and electrolyte leakage (b) in aerial parts of Cakile maritima as function of salinity $(0,100$ and $400 \mathrm{mM} \mathrm{NaCl})$ and physiological development stage (vegetative and flowering). Means (three replicates) followed by at least one same letter are not significantly different at $\mathrm{P}<0.01$.

condensed tannins, these compounds seem to be not affected by salinity at the vegetative period (Table 2). This result was confirmed by ANOVA statistical analysis (Table 1) which showed that (D) contributed with the highest proportion of total variance.

The observed stimulatory effect of salinity on phenolic contents led us to investigate on the activity of two enzymes belonging to the shikimate and phenylpropanoid pathways, involved in phenolic
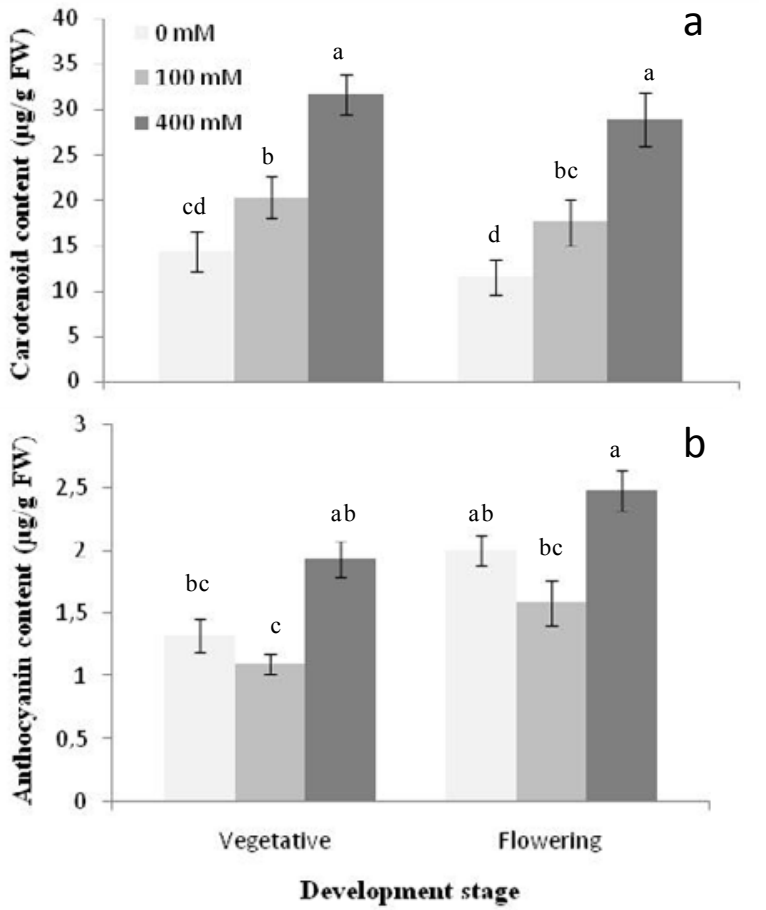

Figure 2: Variation of carotenoid (a) and anthocyanin (b) contents in Cakile maritima aerial parts as function of salinity $(0,100$ and $400 \mathrm{mM} \mathrm{NaCl})$ and physiological development stage (vegetative and flowering). Means (three replicates) followed by at least one same letter are not significantly different at $\mathrm{P}<0.01$

synthesis: SK and PAL.

As shown in Figure 5a, PAL activity increased with salinity regardless the development growth. The analysis of variance (ANOVA) showed the high influence of each factor (S) and (D) and their interaction ( $\times$ $\mathrm{D})$. This activity is as much higher as the salt treatment is stronger. In fact, at the vegetative stage, the PAL activity increase by $19 \%$ at $400 \mathrm{mM}$ as compared to the control, however, it is more pronounced during the 
Citation: Mansour RB, Dakhlaouia S, Msahli W, Ksouri R, Megdiche-Ksouri W (2018) Differential Responses of Cakile maritima at Two Development Stages to Salinity: Changes on Phenolic Metabolites and Related Enzymes and Antioxidant Activity. Med Chem (Los Angeles) 8: 100-108. doi: $10.4172 / 2161-0444.1000500$

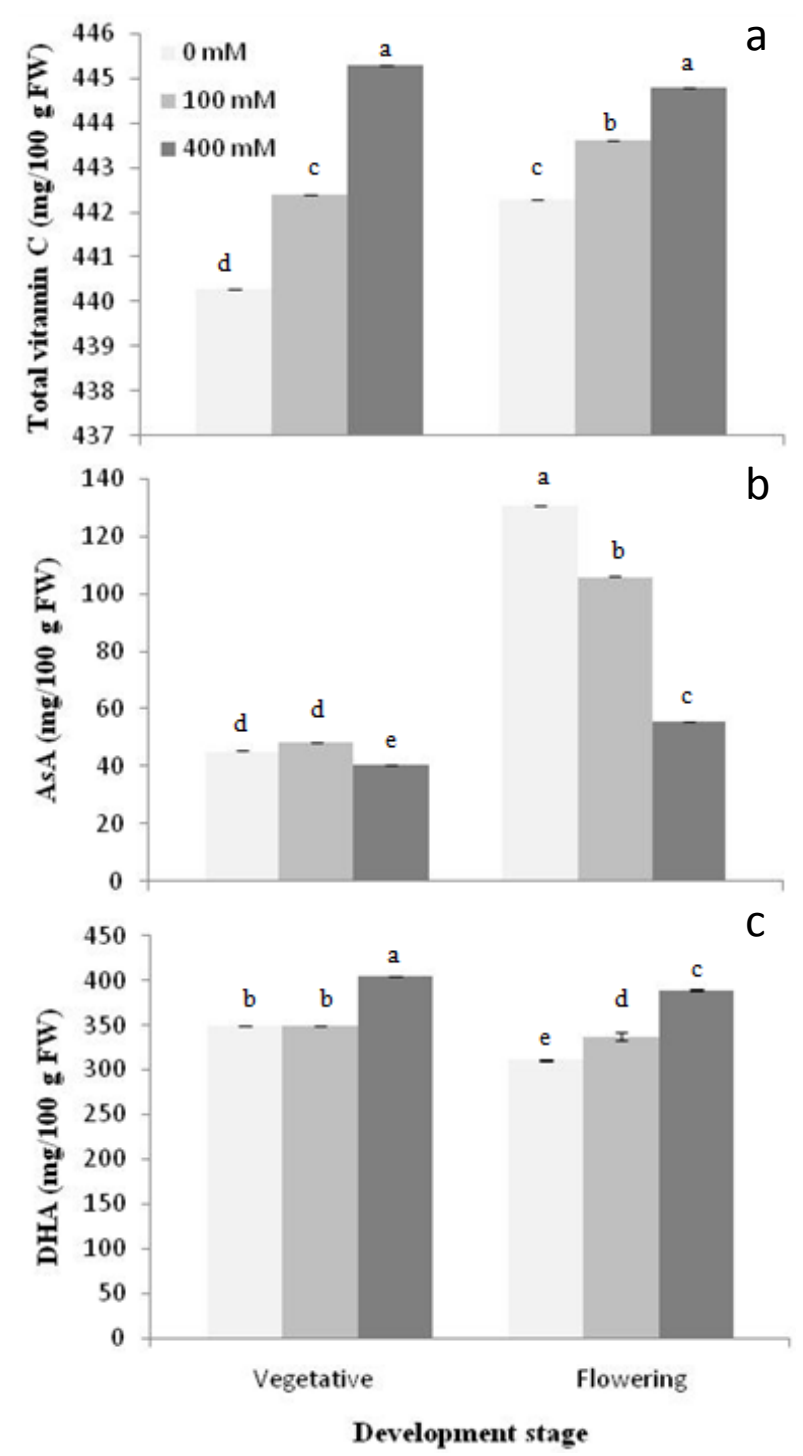

Figure 3: Variation of ascorbic acid (total (a), reduced ascorbate (b) and dehydroascorbate (c)) contents of in aerial parts of Cakile maritima as function of salinity $(0,100$ and $400 \mathrm{mM} \mathrm{NaCl})$ and physiological development stage (vegetative and flowering). Means (three replicates) followed by at least one same letter are not significantly different at $P<0.01$.

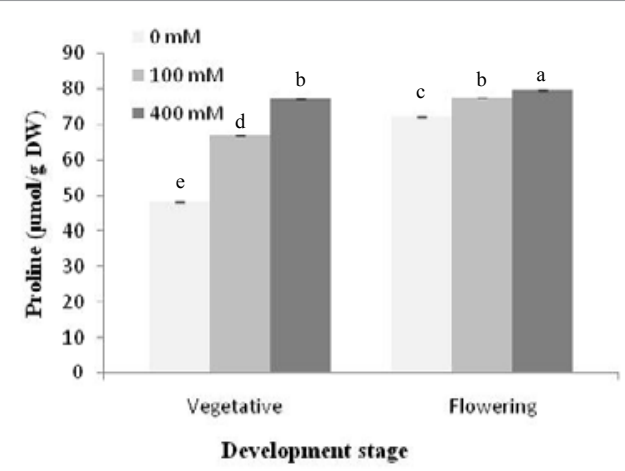

Figure 4: Variation of proline content $(\mu \mathrm{mol} / \mathrm{g} \mathrm{DW})$ in the aerial parts of Cakile maritima as function of salinity $(0,100$ and $400 \mathrm{mM} \mathrm{NaCl})$ and physiological development stage (vegetative and flowering). Means (three replicates) followed by at least one same letter are not significantly different at $P<0.01$.

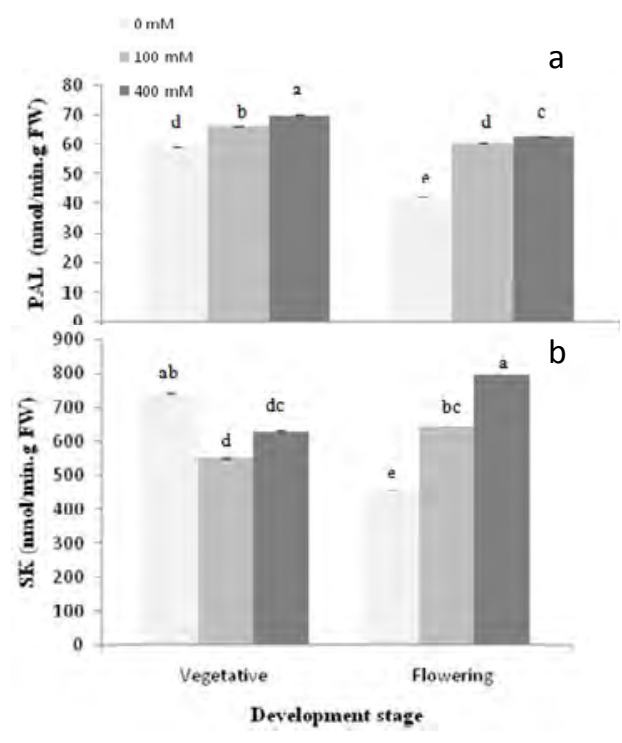

Figure 5: Variation of PAL total activity (nmol trans-cinnamic acid/min.g FW) (a) and shikimate kinase total activity (nmol NADH/min.g FW) (b) in the aerial parts of C. maritima as function of salinity $(0,100$ and $400 \mathrm{mM} \mathrm{NaCl})$ and physiological development stage (vegetative and flowering). Means (three replicates) followed by at least one same letter are not significantly different at $\mathrm{P}<0.01$.

flowering period and goes from $42.3(0 \mathrm{mM})$ to $62.8 \mathrm{nmol} / \mathrm{min} . \mathrm{g} \mathrm{FW}$ (400 $\mathrm{mM}$ ) which is about $48 \%$.

Moreover, the activity of shikimate kinase differs between the two periods of development. It was shown a slight decrease of this activity in first stage at $100 \mathrm{mM}$ followed by an increase at $400 \mathrm{mM}$. However, shikimate kinase activity increased positively with salinity in flowering period (Figure 5b).

\section{Change in antioxidant as function of salinity and physiological development stage}

Total antioxidant activity of the two developmental stages was extremely different (Table 3). Independently of the treatment, this ability was two-fold higher in the vegetative stage (between 29.6 and $34 \mathrm{mg} \mathrm{AGE} / \mathrm{g} \mathrm{DW}$ ) than that in flowering one (between 11.6 and 20 mg AGE/g DW). In addition, the ANOVA analysis (Table 1) indicated that the significant influence on this activity is essentially based on the physiological stage than the salt treatment. As salinity progressed, the antioxidant activity increased in the shoots of C. maritima and was in proportion with the total phenols. Hence, the addition of $\mathrm{NaCl}$ in the culture medium increased the TAA of about $8.5 \%$ and $11.5 \%$ in the vegetative stage and of $30 \%$ and $59 \%$ in the reproductive one, at 100 and $400 \mathrm{mM}$, respectively. In this context, Petridis et al. [35] observed an enhancement of the antioxidant activity of shoots and roots of four olive cultivars under saline conditions. The same authors showed that this increase is usually correlated to the polyphenol contents.

The magnitude of $\mathrm{DPPH}$ radicals quenching activity seemed to be related to the physiological stage and $\mathrm{NaCl}$ treatment too, as $\mathrm{IC}_{50}$ values largely differed between the two periods (Table 3 ). The highest antiradical activity was recorded for the plants treated with $400 \mathrm{mM}$ $\mathrm{NaCl}$ at both stages and it reached $240 \mu \mathrm{g} / \mathrm{ml}$ (vegetative period) and $480 \mu \mathrm{g} / \mathrm{ml}$ (flowering period) and it was even more important at the first period than in the flowering one. Our results corroborate with other authors, which have mentioned the positive correlation between the increase of the antioxidant activity and the salinity tolerance in many plants such as in pea, tomato and citrus [36]. 
The evaluation of the $\mathrm{Fe}^{3+}$ reducing power of shoots extracts is shown in Table 3. The trend for ferric ions reducing activity of the different growth periods showed a similar tendency as compared to their DPPH radical scavenging activities, when a comparison between $\mathrm{EC}_{50}$ and $\mathrm{IC}_{50}$ propensities is made. In fact, vegetative stage showed relatively the stronger ferric ion reducing activity reflected by low $\mathrm{EC}_{50}$ values, as compared to the flowering stage ones.

Furthermore, physiological development stage (D) followed by salt treatment (S) seem to be the determinant factors in the values of this activity as it was depicted by the analysis of variance (Table 1). This activity increased with salinity and the $400 \mathrm{mM}$ treated vegetative plant extracts appeared to possess the highest reducing activity. The reducing power is an important aspect for the estimation of the antioxidant activity which might be due to the reduction of superoxide anion, inactivation of free radicals or complexion with metal ions or combination of the three [1]

In the $\beta$-carotene/linoleate system, free radicals arising from the oxidation of linoleic acid react with the insaturated molecules of $\beta$-carotene and leads to rapid discolouration of the orange solution. The presence of antioxidant reduces this discolouration by inhibiting the lipid peroxydes [37]. Methanolic extracts of Cakile prevented the bleaching of the $\beta$-carotene on a dose dependent manner. At $400 \mathrm{mM}$ of $\mathrm{NaCl}$, shoots displayed the highest capacity of inhibiting the lipid peroxides as compared to different treatment with the lowest $\mathrm{IC}_{50}$ value $(3.7 \mathrm{mg} / \mathrm{ml})$ from vegetative stage. These findings corroborate with polyphenols contents. Moreover, $\mathrm{IC}_{50}$ decreased as the salinity was increased in the culture medium, indicating that the antioxidant capacity of the shoots extracts was stimulated by salt treatment.

\section{Discussion}

Electrolyte leakage and MDA level were commonly known as markers of oxidative stress and the antioxidant status. It is noteworthy that the magnitude of the oxidative stress increased with the salinity. It has been frequently reported that salt stress increased the level of lipid peroxidation and induces oxidative stress in plant tissues expressed as EL [34] and our results, agree with those of Ksouri et al. [14] and Ben Amor et al. [34].

Salinity differently affects the antioxidant molecules equipment of plants. The degree of oxidative cellular damages in plants exposed to this stress is controlled by the capacity of protection against oxidative agents. The involvement of the no-enzymatic system constituted by antioxidant molecules is important in the detoxification of several ROS. Salt tolerance seems to be favored by an increased antioxidative capacity to detoxify reactive oxygen species. Amount of antioxidant pigments, proline, ascorbic acids and phenolics were enhanced in the presence of salt particularly at $400 \mathrm{mM} \mathrm{NaCl}$ for both development stages. Our results are, in fact, in agreement with previous works reporting the seasonal variation of phenolic contents and antioxidant activities [4,38]. Carotenoids and anthocyanins are classified among the compounds having antioxidant activity [12]. In plant, carotenoids have a photoprotective role either by dissipating the excess of energy or by quenching the ROS that naturally occur during photosynthesis or by inhibiting the lipid peroxidation [39]. Besides, $\beta$-carotene cooperates with tocopherols in the radical scavenging capacity within the inner part of lipid membranes [40]. It has also been reported a positive correlation between antioxidant capacity and anthocyanins content in blackberries, red raspberries and strawberries [38]. Also, many studies confirmed the role of vitamin $\mathrm{C}$ as a powerful antioxidant and its implication in neutralizing the ROS [39-42]. In addition, the comparison of ascorbic acid content with other conventionally rich plant sources of this vitamin such as carrots $(6 \mathrm{mg} / 100 \mathrm{~g} \mathrm{FW})$, bananas (10-30 mg/100 g FW), citrus ( $40-50 \mathrm{mg} / 100 \mathrm{~g} \mathrm{FW})$, spinach $(51 \mathrm{mg} / 100$ $\mathrm{g} \mathrm{FW})$ and tomato $(20-25 \mathrm{mg} / 100 \mathrm{~g} \mathrm{FW})$ [43] indicated that C. maritima is an important source of this natural antioxidant potentially beneficial to human health. Besides, proline accumulation normally occurs in the cytosol where it contributes substantially to the cytoplasmic osmotic adjustment [3]. In addition to this role, it contributes to stabilizing subcellular structures, scavenging free radicals and buffering cellular redox potential under stress conditions [44].

Plants widely vary in their phenolic composition and contents, with both physiological periods and environments affecting the kind and level of phenolic compounds [38]. Our results corroborate with many works that reported the increase of phenolic compounds under increasing salinity $[45,46]$ and showed that this increase mitigates the ionic effect of $\mathrm{NaCl}$ [47]. These compounds seem to possess a huge role in ameliorating the stress defense of the plant and interfere as efficient antioxidant substances.

The total phenolic content differed slightly among the two studied physiological stages of the plant. However, extracts with higher phenolic content did not always have higher flavonoid and tannin contents, as was evident for salt-challenged plant extracts from the flowering period which had a higher total flavonoid and tannin contents compared with those of vegetative plants (Table 2), although the total phenolic content was lower in the second developmental period compared to the first one (Table 2). These results suggest that different salt-stressed plant extracts of each period contain different levels of total flavonoids as a proportion of the total phenolic compounds [48]. Despite the fact that our results have shown that phenolic compounds content varies slightly depending on the development stages, those of the antioxidant activities exhibited a marked difference from the vegetative to the flowering periods. These data are in agreements with Ksouri et al. [4], where they found that leaves and stems of Salsola kali have an important antioxidant activity in the vegetative stage. This might suggest that these compounds play different roles depending on the state of the plant which could lead us to believe that, during flowering, these molecules are moving more toward a physiological role. While during the vegetative stage, they act preferentially as protector of plants by acting primarily as antioxidants. This proposal has been verified by many previous research works which confirmed the role of phenolics as major antioxidants in plants, especially within halophytic species $[4,38]$.

The activity of enzymes involved in phenolic synthesis (SK and PAL) was also affected by salinity and showed significant differences as function of salt doses and development stages. The PAL activity can differ depending on the physiological stages, genotype and environmental factors [49]. Several studies reported that this activity is highly influenced by many abiotic and biotic factors [50]. Gao et al [51] reported an increase in the PAL activity in Jatropha curcas leaves after a treatment with copper. Similarly, Kovacik et al. [52] had showed that a nitrogen deficiency in Matricaria chamomilla leads to a rise in the enzyme total activity of $61 \%$ compared to control. The induction of enzymes of the shikimate pathway under different kinds of abiotic stress was previously demonstrated. Msehli et al. [53] had shown that SK activity increased with Fe deficiency in the species Medicago ciliaris.

In fact, the induction of the PAL is associated with the accumulation of secondary compounds of the phenylpropanoids that provides specific protections to plants against stress [54]. Many studies indicated that the activation of the PAL and the increase of the phenolic content in plants represent a general response associated to the resistance to 
Citation: Mansour RB, Dakhlaouia S, Msahli W, Ksouri R, Megdiche-Ksouri W (2018) Differential Responses of Cakile maritima at Two Development Stages to Salinity: Changes on Phenolic Metabolites and Related Enzymes and Antioxidant Activity. Med Chem (Los Angeles) 8: 100-108. doi: 10.4172/2161-0444.1000500

stress [55]. Moreover, besides their role in the primary metabolism, enzymes of the shikimate pathway constitute an essential link with the secondary metabolism and the shikimate kinase plays a regulation role facilitating the orientation to specific secondary compounds [56]. Thus, the simultaneous activation of enzymes from the shikimate and the phenylpropanoid pathways in order to produce phenolic compounds can be considered as an efficient response to salt stress.

\section{Conclusion}

No-enzymatic molecules contents and antioxidant activities depend on several factors, mainly environmental conditions, and their salt-tolerance limits are greatly influenced by endogenous (that is, physiological development stage) and exogenous factors (that is, salinity). Our results demonstrated the influence of salt conditions and period of growth on the evolution of bioactive compounds such as phenolics and ascorbic acid and antioxidant activity of C. maritima. It can be stated that both endogenous factor (D) and exogenous factor (S) and their interaction were highly implicated on the polyphenol biosynthesis and quality.

The increase of bioactive compound amounts and antioxidant capacities confirmed the stimulation of their synthesis in presence of salt constraint and their role as protectors of plant structures against the oxidative stress. In fact, the nature and the complexity of the plants bioactive substances influence their activities. The parallel induction of enzymes of the phenylpropanoid and shikimate pathways came also to confirm the tolerance of C. maritima to salinity.

\section{Acknowledgments}

This work was supported by the Tunisian Ministry of Higher Education and Scientific Research (LR15CBBC06).

\section{References}

1. Ksouri R, Falleh H, Megdiche W, Trabelsi N, Mhamdi B, et al. (2009) Antioxidan and antimicrobial activities of the edible medicinal halophyte Tamarix gallica L. and related polyphenolic constituents. Food and Chemical Toxicology 47: 2083-2091.

2. Boughalleb F, Denden M, Benb TB (2009) Anatomical changes induced by increasing $\mathrm{NaCl}$ salinity in three fodder shrubs, Nitraria retusa, Atriplex halimus and Medicago arborea. Acta Physiologia Plantarum 31: 947-960.

3. Megdiche W, Passaquet C, Zourrig W, Zouily FY, Abdelly C (2009) Molecula cloning and characterization of novel cystatin gene in leaves Cakile maritima halophyte. Journal of Plant Physiology 166: 739-749.

4. Ksouri R, Megdiche W, Falleh H, Trabelsi N, Boulaaba M, et al. (2008) Influence of biological, environmental and technical factors on phenolic content and antioxidant activities of Tunisian halophytes. Compte Rendus de Biologie 331: 865-873.

5. de Abreu IN, Mazzafera P (2005) Effect of water and temperature stress on the content of active constituents of Hypericum brasiliense Choisy. Plant Physiology and Biochemistry 43: 241-248.

6. Hartmann DM, Bourenkov PG, Oberschall A, Strizhov N, Bartunik DH (2006) Mechanism of Phosphoryl Transfer Catalyzed by Shikimate Kinase from Mycobacterium tuberculosis. Journal of Molecular Biology 364: 411-423.

7. Boudet AM (2007) Evolution and current status of research in phenolic compounds. Phytochemistry 68: 2722-2735.

8. Nugroho LH, Verberne MC, Verpoorte R (2002) Activities of enzymes involved in phenylpropanoid pathway in constituvelly salicylic acid-producing tobacco plants. Plant Physiology and Biochemistry 40: 755-760.

9. Chaman ME, Copaja SV, Argandona VH (2003) Relationship between salicylic content, phenylalanine ammonia-lyase (PAL) activity, and resistance of barley to aphid infestation. Journal of Agricultural Food Chemistry 51: 2227-2231.

10. Smirnoff N, Wheeler GL (2000) Ascorbic acid in plants: biosynthesis and function. Critical Review of Plant Sciences 19: 267-290.
11. Bartoli CG, Pastori GM, Foyer CH (2000) Ascorbate biosynthesis in mitochondria is linked to the electron transport chain between complexes III and IV. Plant Physiology 123: 335-343.

12. Lisiewska Z, Kmiecik W, Korus A (2006) Content of vitamin C, carotenoids, chlorophylls and polyphenols in green parts of dill (Anethum graveolens L.) depending on plant height. Journal of Food Composition and Analysis 19: 134140.

13. Toor GS, Hunger S, Peak JD, Sims J, Sparks DL (2006) Advances in the characterization of phosphorus in organic wastes: Environmental and agronomic applications. Advances in Agronomy 89: 1-72

14. Ksouri R, Megdiche W, Debez A, Falleh H, Grignon C, et al. (2007) Salinity effects on polyphenol content and antioxidant activities in leaves of the halophyte Cakile maritima. Plant Physiology and Biochemistry 45: 244-249.

15. Oueslati S, Karray BN, Attia H, Rabhi M, Ksouri R, et al. (2010) Physiological and antioxidant responses of Mentha pulegium (Pennyroyal) to salt stress. Acta Physiologia Plantarum 32: 289-296.

16. Hewitt EJ (1966) Sand and water culture methods used in the study of plant nutrition. Technical Communication No. 22. Revised 2nd edn. Com Bur of Horticultural and Plant Crops East Malling, Maidstore, Kent.

17. Cakmak I, Horst JH (1991) Effect of aluminum on lipid peroxidation, superoxide dismutase, catalase, and peroxidase activities in root tips of soybean (Glycine max). Physiologia Plantarum 83: 463-468.

18. Gould KS, Markham KR, Smith RH, Goris JJ (2000) Functional role of anthocyanins in the leaves of Quintinia serrata A. Cunn. Journal of Experimental Botany 51: 1107-1115.

19. Murray JR, Hackett WP (1991) Dihydroflavonol reductase activity in relation to differential anthocyanin accumulation in juvenile and mature phase Hedera helix L. Plant Physiology 97: 343-351.

20. Kampfenkel K, Van Montau M, Inze D (1995) Extraction and determination of ascorbate and dehydrascorbate from plant tissue. Analytical Biochemistry 225: 165-167.

21. Bates LS, Waldren RP, Teare ID (1973) Rapid determination of free proline in water stress studies. Plant and Soil 39: 205-208.

22. Dewanto V, Wu X, Adom KK, Liu RH (2002) Thermal processing enhances the nutritional value of tomatoes by increasing total antioxidant activity. Journal of Agriculture and Food Chemistry 50: 3010-3014.

23. Sun B, Richardo-da-Silvia JM, Spranger I (1998) Critical factors of vanillin assay for catechins and proanthocyanidins. Journal of Agriculture and Food Chemistry 46: 4267-4274.

24. Dìaz J, Rosbrcelò A, Merino de caceres $F$ (1997) Changes in shikmate dehydrogebinase and end products of the shikimate pathway, chlorogenic acid and lignin's during the early development to seedlings of (Capsicum annumm L.). New Phytol 136: 183-188.

25. Krell T, Maclean J, Boam DJ, Cooper A, Resmini M, et al. (2001) Biochemica and X-ray crystallographic studies on shikimate kinase: The important structura role of the P-loop lysine. Protein Science 10: 1137-1149.

26. Cahill DM, McComb JA (1992) A comparison of changes in phenylalanine ammonia-lyase activity, lignin and phenolic synthesis in the roots of Eucalyptus calophylla (field resistant) and E. Marginata (susceptible) when infected with Phytophthora cinnamomi. Physiology and Molecular Plant Pathways 40: 315332.

27. Prieto P, Pineda M, Aguilar M (1999) Spectrophotometric quantitation of antioxidant capacity through the formation of phosphomolybdenum complex: Specific application to the determination of vitamin E. Analytical Biochemistry 269: 337-341.

28. Hanato T, Kagava H, Yasuhara T, Okuda T (1988) Two new flavonoids and other constituents in licorice root their relative astringency and radical scavenging effect. Chemical and Pharmaceutical Bulletin 36: 1090-1097.

29. Oyaizu M (1986) Studies on products of browning reaction prepared from glucoseamine. Japanese Journal of Nutrition 44: 307-314.

30. Koleva II, Van Beek TA, Linssen JPH, de Groot A, Evstatieva LN (2002) Screening of Plant Extracts for Antioxidant Activity: a Comparative Study on Three Testing Methods. Phytochemical Analysis 13: 8-17.

31. Debez A, Koyro HW, Grignon C, Abdelly C, Huchzermeyer B (2008) Relationship between the photosynthetic activity and the performance of Cakile 
Citation: Mansour RB, Dakhlaouia S, Msahli W, Ksouri R, Megdiche-Ksouri W (2018) Differential Responses of Cakile maritima at Two Development Stages to Salinity: Changes on Phenolic Metabolites and Related Enzymes and Antioxidant Activity. Med Chem (Los Angeles) 8: 100-108. doi: 10.4172/2161-0444.1000500

maritima after long-term salt treatment. Physiologia Plantarum 133: 373-385

32. Hafsi C, Romero-Puertas MC, Gupta DK, Del Rio LA, Sandalio LM, Abdelly C (2010) Moderate salinity enhances the antioxidative response in the halophyte Hordeum maritimum L. under potassium deficiency. Environmental and Experimental Botany 9: 129-136.

33. Telesinski A, Nowak J, Smolik B, Dubowska A, Skrzypiec N (2008) Effect of soil salinity on activity of antioxidant enzymes and content of ascorbic acid and phenols in bean (Phaseolus vulgaris L.) plants. Journal of Elementology 13: 401-409.

34. Amor BN, Jimenez A, Megdiche W, Lundqvist M, Sevilla F, et al. (2007) Kinetics of the Antioxidant Response to Salinity in the Halophyte Cakile maritima. Journal of Integrative Plant Biology 49: 1024-1034.

35. Petridis A, Theriosa I, Samouris G, Tananaki C (2012) Salinity-induced changes in phenolic compounds in leaves and roots of four olive cultivars (Olea europaea L.) and their relationship to antioxidant activity. Environmental and Experimental Botany 79: 37-43.

36. Jithesh MN, Prashanth SR, Sivaprakash KR, Parida AK (2006) Antioxidative response mechanisms in halophytes: their role in stress defence. Journal of Genetics 85: 237-254.

37. Godevac D, Vujisic L, Mojovic M, Ignjatovic A, Spasojevic I, et al. (2008) Evaluation of antioxidant capacity of Allium ursinum L. volatile oil and its effect on membrane fluidity. Food Chemistry 107: 1692-1700.

38. Jallali I, Megdiche W, M'Hamdi B, Oueslati S, Smaoui A, et al. (2012) Changes in phenolic composition and antioxidant activities of the edible halophyte Crithmum maritimum L. with physiological stage and extraction method. Acta Physiologia Plantarum 34: 1451-1459.

39. Gill S, Tuteja N (2010) Reactive oxygen species and antioxidant machinery in abiotic stress tolerance in crop plants. Plant Physiology and Biochemistry 48 . 909-930.

40. Tsuchihashi $H$, Kigoshi M, Iwatsuki M, Niki E (1995) Action of $\beta$-carotene as an antioxidant against lipid peroxidation. Archive in Biochemistry and Biophysics 323: $137-147$.

41. Araceli CO, Ma LPH, Ma EPH, Jose AR, Carlos AGV (2009) Chemical studies of anthocyanins: A review. Food Chemistry 113: 859-871.

42. Yabuta Y, Mieda T, Rapolu M, Nakamura A, Motoki T, et al. (2007) Light regulation of ascorbate biosynthesis is dependent on the photosynthetic electron transport chain but independent of sugars in Arabidopsis. Journal of Experimental Botany 58: 2661-2671.

43. Davey MW, Montagu MV, Inze D (2000) Plant L-ascorbic acid: chemistry, function, metabolism, bioavailability and effects of processing. Journal of
Sciences and Food Agriculture 80: 825-860.

44. Ashraf M, Foolad MR (2007) Roles of glycinebetaine and proline in improving plant abiotic stress tolerance. Environmental and Experimental Botany 59: 206216

45. Agastian P, Kingsley SJ, Vivekanandan M (2000) Effect of salinity on photosynthesis and biochemical characteristics in mulberry genotypes. Photosynthetica 38: 287-290.

46. Yuan G, Wang X, Guo R, Wang Q (2010) Effect of salt stress on phenolic compounds, glucosinolates, myrosinase and antioxidant activity in radish sprouts. Food Chemistry 121: 1014-1019.

47. Muthukumarasamy M, Gupta SD, Panneerselvam R (2000) Enhancement of peroxidase, polyphenol oxidase and superoxide dismutase activities by triadimefon in $\mathrm{NaCl}$ stressed Raphanus sativus L. Biologia Plantarum 43: $317-$ 320

48. Maisuthisakul P, Suttajit M, Pongsawatmanit R (2007) Assessment of phenolic content and free radical-scavenging capacity of some Thai indigenous plants. Food Chemistry 100: 1409-1418.

49. Khan W, Prithiviraj B, Smith L (2003) Chitosan and chitin oligomers increase phenylalanine ammonia-lyase and tyrosine ammonia-lyase activities in soybean leaves. J Plant Physiology 160: 859-863.

50. Rivero RM, Ruiz M, Garcia PC, Lopez-Lefebere LR, Sanchez E, et al. (2001) Resistance to cold and heat stress: accumulation of phenolic compounds in tomato and watermelon plants. Plant Sciences 160: 315-321.

51. Gao S, Yan R, Cao M, Yang W, Wang S, et al. (2008) Effects of copper on growth, antioxidant enzymes and phenylalanine ammonia-lyase activities in Jatropha curcas L. seedling. Plant Soil Environ 54: 117-122.

52. Kovacik J, Klejdus B, Backor M, Repcak M (2007) Phenylalanine ammonialyase activity and phenolic compounds accumulation in nitrogen-deficient Matricaria chamomilla leaf rosettes. Plant Sciences 172: 393-399.

53. Msehli W, Dell'orto M, Donnini S, De Nisi P, Zocchi G, et al. (2009) Variability of metabolic responses and antioxidant defense in two lines of Medicago ciliaris to Fe deficiency. Plant Soil 320: 219-230.

54. Sarma AD, Sharma R (1999) Purification and characterization of UV-B induced phenylalanine ammonia-lyase from rice seedlings. Phytochemistry 49: 618-626.

55. Vimala R, Suriachandraselvan M (2009) Induced resistance in bhendi against powdery mildew by foliar application of salicylic acid. Journal of Biopesticides 2: $111-114$.

56. Fucile G, Falconner S, Christendat D (2008) Evolutionary diversification of plant shikimate kinase gene duplicates. PloS Genetics 4: 1-15. 